Zarifa G. Jabrayilova

Institute of Information Technology of ANAS, Baku, Azerbaijan

depart15@iit.ab.az

DOI: 10.25045/jpis.v07.i2.06

\title{
FORMATION OF HUMAN RESOURCES FOR E-HEALTH: INTERNATIONAL EXPERIENCE, SOLUTIONS AND PERSPECTIVES
}

The introduction and use of information and communication technologies (ICT) in health care, including e-health formation, and the realization of electronic medical cards, requires the appropriate human resources with necessary skills and knowledge. This article represents the topicality of the personnel shortage problem on IT specialties for health care - health informatics. The challenges on this problem solution in several countries, with succefully developed $e$-medicine, are analyzed. The programs and strategies for the solution of personnel education and training on the specialties of health informatics are analyzed. The development on personnel training in the integration of medicine and ICT in Azerbaijan are stated, and the recommendations are put forward.

Keywords: human resources in electronic health, health informatics, health informatician, health information manager, health cybernetics.

\section{Introduction}

The dynamic development and comprehensive application of ICT in all spheres of activity has led to the fundamental changes in these spheres. Consequently, all of these spheres of activity, their structures, forms and methods, development trends have undergone a serious transformation [1]. The formation of e-health is a good example. The development of ICT in the world has left the traditional services of health care system behind. Now, the medical information systems and EHR developed with the growth of ICT are used to support continuous medical assistance in separate medical institutions and regions [2]. These systems serve as the tools to support decision-making of geographically distributed users, doctors and the patients. They provide the accessibility of the knowledge base obtained from the clinical practice, and also increase the productivity and quality of the healthcare. Such systems enable everyone to get important information in the right place at the right time, which is very important for handling the situation by providing the necessary assistance in unpleasant situations. The countries with advanced E-healthcare mainly focus on the creation of suitable infrastructure (e-health) to provide better services to the enterprises, regions, and people connected to the health information system and network. Since the health information systems become common in the healthcare system and the traditional medical record keeping is replaced by the information systems and data analytics, the nature of the service provided to the patients is also changing. This is putting forward new demands on the performance of the highly qualified staff in the health care system, and at the same time, requires the integration of the experts in computer science into the health system. According to the experience of the national schools, which have achieved successful results in this field, the whole world has already realized that a key component of the integration of ICT in medicine is the human resources with necessary skills and knowledge. This need has been first reflected in the UK health programs [3], and then Australia and Canada began to focus on the development of the workforce of e-medicine [4, 5]. Health Information Technology for Economic and Clinical Health (HITECH) adopted in the US, which provides "constructive use" of the EHR system, emphasizes investing in the labor force [6]. Currently, it is of particular importance to develop human resource in e-medicine, and to design a data management support system, which collects medical data with high quality, and to train IT specialists to be in charge of the necessary technical equipment. Through e-Health, an infrastructure has been introduced as a tool connecting to the world; this infrastructure cannot be realized without the specialists in health informatics $[7,8]$. Continuously generating health data and data sets cannot be managed, 
used and applied without the skills and professionalism required in this area. As the implementation of the national e-Health requires the specialists with the specific skills, they should also have ICT knowledge. Along with the deep understanding of the health care system, these professionals must have the knowledge in:

- reengineering and project management;

- health data collection, security and confidentiality;

- human factor and technological processes;

- technologies and supporting mechanisms providing access to the information systems [9].

The development of human resource strategy to meet the healthcare demands is challenging.

On the other hand, along with IT knowledge, the medical IT professionals should also have knowledge in medicine, business and management. According to 88\% of IT Directors of 91 institutions providing information services, they believe that the comprehension of health care system and the essence of the medical data is the major factor for the successful operation of IT practitioners working in the medical institutions [10]. Thus, this article explores the experience of the countries in training the specialists in the field of health informatics, in which successful results in e-Health formation have been attained. The article analyzes the attempts made in the "road map" of these achievements for the human resources development in medicine. Grounding on the international practice, the recommendations on the formation of human resources in ehealth in Azerbaijan are put forward.

\section{e-Health human resource challenges}

The strategy for the training of human resources in e-Health is important for the health data collection, security and confidentiality, and for the high quality use of the system and data in the future [2]. To achieve the final results based on EHR, the employees must correctly use and manage the health data contained there. These employees are:

- $\quad$ specialists in health informatics or health informaticians (HI);

- $\quad$ health information managers (HIM);

- specialists with ICT skills, and the knowledge in confidentiality and security of health records; human factor and technological processes; project management and technology application; experts capable to interoperate the user-server platforms and being aware of health care systems and data standards.

The workers undertake the task to promote the health care system with the use of ICT. The development of human resources strategy for e-Health is very difficult. Because, the traditional supply and demand models used for the qualification and distribution of the doctors, nurses and other medical workers should include these innovations.

To meet the demand for health informaticians, the UK and Australia adopted a national strategy, in 2002 and 2003, and later in 2009 [11-13].

The UK National Health Service allocated $£ 12.4$ billion for a 10 -year national IT program to improve the safety and quality of medical care, and to realize e-Health and EHR system [14]. The program states that "the lack of qualified human resources is a serious obstacle to the realization of e-Health", thus, there is a high demand for skilled medical workers, but supply is very low. The UK National Health Service proves that "the lack of workforce with the experience in IT applications and medical knowledge is a real obstacle to the realization of the medical project."

[15] notes that, in Canada, for the realization of e-Health resources, at least \$ 7-10 billion are required, as the result of which 9000 health informaticians should be trained. The lack of IT resources is affecting the development pace of the projects realized in the field health care informatization in an entire country. Although financial support for the e-Health projects has increased, the qualified human resources have not been supplied, and the shortage of professional 
health informaticians still remains "a serious risk for achieving a success in EHR initiatives" [16, 17]. [16] states that Canadian Health Informatics Association, Canadian Association for Health Information Management, the Health Sector of the Canadian Association for Information Technologies, Canadian Infoway health structure and the Canadian Board of information and communications technologies started a joint research on defining the experts in national health informatics and health informatics management and on counting their number in e-Health.

The US Altarum Institute offers 3-point evaluation in order to define the demand for human resources for the establishment of a national health information network within 5 years [18]:

1. complete introduction and operation of EHR system in hospitals;

2. complete introduction and operation of EHR system in hospitals and other medical facilities;

3. availability of medical IT professionals necessary for the creation of medical infrastructure, which provides the inclusion of health records from various sources in EHR and the access of each doctor and patient to EHR, more precisely, which ensures the relationship between all the systems.

It is estimated that 400000 physicians are required for practical use, and 7,600 more specialists - for the complete operation of EHR system, and 28600 experts in about 4000 hospital that need EHR system, and finally, 420 professionals are required for the installation of health information infrastructure [18]. These figures made the history, as the first quantitative indicators for the assessment of the demand for human resources to establish the national health information network.

The databases of health information management service centers of the 5000 American hospitals show that, currently, 40784 IT specialists are needed in order to get the complete EHR based on all registered electronic health data [7].

The survey conducted among the health information managers shows that, approximately, $53 \%$ of them were clinic or office doctors mainly employed in the inpatient and outpatient hospitals earlier, and about $19 \%$ of them were the employees of consulting firms [19].

At present, challenges related to the human resources in these countries are associated with the following problems [2]:

- $\quad$ certification of the specialists in health information management (Canada and the US have already started this process);

- $\quad$ certification of the specialists with necessary e-Health skills or regulating the licenses and providing legal base;

- $\quad$ training and search of people with appropriate skills to become a part of necessary workforce in e-Health;

- coordination of the strategy of e-Health staffing with the public health (healthcare) model.

\section{e-Health professionals and their competencies}

[20] defines e-Health as follows: "e-Health is the field developing at the intersection of health informatics, health care and business based on the transfer of health and information services over the Internet and related technologies. In a wider sense, the term characterizes not only the technical development, but also the level of cognition and thinking manner to improve the healthcare in the regions and all over the world through ICT. Thus, e-Health means computer applications, methods, tools applied in health system and the people performing all of these (suppliers, administrators, patients, families). For example, the studies and implementations conducted in the field of computer science are introduced to e-Health jointly by health information managers, researchers, technical experts and other field specialists [7, 9]. The professionals working in this field are called "e-Health experts". 
e-Health professionals are using the concepts of computer science, methods and tools by bringing them together to support healthcare processes. e-Health professionals are referred to the health informaticians, health information managers, technical professionals and the specialists from various professions, who are capable to apply the concepts, methods and tools of computer science in e-Health to improve the effectiveness of healthcare system.

Health informaticians - specialists with the competencies of health informatics in e-Health. Health informatics is a discipline which studies the research, development, design, implementation and evaluation of the data related to the concepts, methods and tools supporting the healthcare procedure and medical administration. [11, 12] define the term "health informatics", and interpret the habits, skills and knowledge of these qualification owners. They are regarded as the e-Health professionals, and called "the owners of knowledge and skills providing collection, processing and access to the health data, which supports the provision of health services." This definition also determines the future distribution of health informaticians. They are ICT experts (creators, rulers and supporters of ICT infrastructure - currently approximately 37\%), EHR-creators, developers, and executors (data organizers, who match and choose the information about the patient - currently approximately 26\%). [21] classifies the health informaticians as follows:

- applied health informaticians are the professionals, who are deeply aware of the fundamental concepts of health. They apply the methods (including planning, management, analytics, procedures, etc.) to support the health processes and carrying out the installation of tools (e.g., information and communication systems). Their competencies are explained in [11] in details. One can master this profession with the Bachelor's degree or certification in the field of medical informatics.

- researcher-health informaticians design, develop and evaluate the concepts, methods and tools of health Informatics. The competence of these experts are provided in the section "exploration and development of health informatics" in the works [3, 4, 11]. The researcher-health informaticians should have the bachelor's or scientific degree in the field of health information science. Those working at the educational institutions in the field of computer science usually tend to have scientific degree of $\mathrm{PhD}$.

The professionals of both fields of computer science can be clinical informaticians, and those who deal with telemedicine, health policy, health informatics visualization, and so on.

Along with these two professionals, clinicians and administrators are also referred to health informaticians. Mastering advanced health informatics enough, they grow as professionals with clinical and administrative skills.

Health information managers (HIM) - the specialist managing the health information of e-health team. The Canadian Association for Health Information directs the scope of the health information managers to the health data. The experts managing the health information operate both at micro and macro levels of clinical information management. At micro level (or personal health record level), health information managers are in charge of collection, use, accessibility, promotion, maintenance, support and destruction of health records regardless of their format. Health information managers perform high quality analysis of EHR documentation and are responsible for the safety of EHR use. Ensuring the security and confidentiality of health information, the managers should be interested in protecting human rights. At macro level (or aggregated data level), the managers realize the statistical analysis of the information contained in the health records. They perform integrated management of information systems by taking into account the interests of the state and individual parties for the improvement of the population's health.

American association for health information management evaluates the health data management as owning the knowledge and practice, which provides access to the HER to support 
decisions in real-time and critical situations. The managers can be presented as a clinical data specialist, the patient information coordinator, a manager of quality data organization, information security manager, information resource administrator, and a decision support expert.

Technical experts - e-health team members with one or more technical qualifications. The systems they mastered may include operating systems, databases, programming languages, software, applied software (production facilities, administrative information systems, office systems, etc.), different equipment, communication and networking tools, biomedical engineering facilities, security, risk management methods, procedures, and so on.

Other experts in health information technologies - refer to the professionals in ICT and business systems, human resource management, and industrial engineering.

\section{e-health specialist training}

Training programs of e-Health specialists, in the best case, are aimed at achieving the intended (projected) number of graduates that are needed to solve the demand problem in the field of e-health. Each year, these programs develop 100 specialists on health informatics and 200 specialist on health information manager in Canada. However, these short-term programs do not provide the demand for human resources in e-health. The short-term strategies also provide the training of the specialists and practitioners in the field of health information management and technical services.

Health informatics school in Canada was formed in 1981. The University of Victoria supports the program at undergraduate and graduate levels. During the previous years, the bachelor's program in health informatics was supported at the University of Dalhousie and Conestoga College, a master's program in health informatics was supported at the University of Dalhousie and the University of Toronto, and e-health is taught at the University of Mcmaster. Health information manager program is taught at the undergraduate level at the University of Ontario.

The available programs offer the opportunity to expand the profile of the profession of health informatics specialists and to get the professional certificate; they also offer marketing, search for the jobs for specialists in e-health, computer science and computer technique [17]. Long-term strategy for human resources is intended to coordinate the training in the field of e-health at all levels (undergraduate and graduate). These programs are accredited by the Canadian Association for Health Information Management, are meant for long-term training of the specialists in health informatics and e-health.

[6] states that 118 million USD was allocated for the training of specialists in e-health within the framework of HITECH program, which is shared among the following areas:

1) vocational training program in health informatics (70 million USD) - short-term certificate programs to train 10000 experts in the colleges;

2) development centers program (10 million USD) - preparation of educational materials in local colleges and a national educational institutions and their distribution through the center;

3) examination program on competences (6 million USD) - testing the local college graduates on their competences;

4) university preparation assistance program (32 million USD) - developing the grants for the training of both undergraduate and graduate-level university students as the workforce with accordance to the certification programs.

Canada and several other countries are going to make changes to the national occupational standards for the development of national health services. [22] provides more attention to this problem and emphasizes the development of professional standards for the qualifications in health informatics as an important issue and justifies the development of the unified code in health information technologies. 
The maintenance of health informaticians becomes challenging in national health care system. In general, there are some problems with satisfying the demand for health informaticians, EHR security, data protection and ICT staff on data development based. $[12,13]$ state that $43 \%$ of employees shifted to the similar positions in the private sector and $29 \%$ in the national health authorities. The reasons for this are low wages in the national sector, high demand, and difficult working conditions. However, mid-level health informaticians often have less problems. However, they also start to look for a better job as their knowledge and skills increase. Senior health informaticians are paid less than in the special sectors by $30-50 \%$. Health informaticians often leave the workplace due to: 1) the lack of qualification and promotion; 2) the difficult working conditions (i.e., stress, unbalanced work regime, etc.); 3) and low wages.

The formation of human resources ensuring successful e-health the following offers are made in [13]:

- to be provided with a workforce in health informatics;

- to develop the effective strategies for the recruitment to fulfill the functions of the position required by the employer;

- to provide the information, which depicts professional portrait of the health informatician and defines his/her future career growth (EHR, information management, information services etc.);

- to attract foreign workforce by providing incentive career growth (to attract those from other local medical clinics or the immigrants with necessary skills);

- to open the vacancies on health informatics in the companies;

- to develop lifelong education strategy;

- to develop the skills appropriate to the stages of the career growth in order to attract a wide range of health informaticians;

- to develop training programs (by different levels) on health informatics to ensure the sustainable development of knowledge, skills and experience for career growth;

- to maintain (to motivate)the workforce on health informatics;

- to ensure decent working environment, including fair wage structure;

- to record and reward achievements;

Australian national action plan mentions the importance of cooperating with the experts from all fields of health care system in order to define the demand for workforce on health informaticians $[3,11]$. According to the Australian experience, it is important to define: first, who needs to study and what should be specifically learnt; second, which skills are vital. The action plan includes the following factors as the reasons for the lack of qualified specialists:

- lack of appropriate educational programs;

- lack of education funding;

- the difficulty of attracting the students due to the unclear results of a health informaticians and health information managers, as they are new careers;

- low wages;

- lack of specialty status;

- new skills required for health informaticians and health information managers, which are still not provided.

- lack of coordination and management;

- lack of a single program in the field of health informaticians and health information managers.

Canada and the United States created the positions of the national coordinator and social service on the problems of healthcare information technologies in the healthcare structures of these states, in order to develop and implement a plan to improve the quality and efficiency of healthcare infrastructure with the use of information technology in 2008-2012 [22]. This plan promised to increase enrollments in health informatics in 2012 by $40 \%$, and by more than $50 \%$ 
in 2014. American Health Information Association administration estimates 4000 unoccupied position of health information manager due to the lack of enough workforce in the United States. It declares the shortage in this profession and stresses that the national health infrastructure will fail without the workforce capable to use and perform advanced technologies [23]. It also states that the increase in the quality and quantity of the workforce in health informatics is a critical component of the transformation of American health care system and ICT. In [7], it is mentioned that in 2014, for the realization of the desired model of the national health infrastructure and general HER system, at least, additional 41000 experts in health information management are required.

In advanced countries with forming E-health system, the national coordination centers and associations support the development of this field not only in their own countries, but also on undeveloped countries. American Association for Health Informatics received a grant of 1.2 million USD from Bill Gates and Melinda Foundation in December 2008 the development of workforce health informatics in the Latin America, Africa, the Middle East, Southeast Asia and the Pacific region countries [24]. The aim was to overcome the personnel shortage in health informatics in these countries, and to solve the problems of biomedicine and health informatics in education and training.

\section{Big Data analytics personnel problems of E-health}

Since 1980, stored digital information doubles every 40 months. Moreover, in recent years, it has been exponentially increasing. The generation of 2.5 Exabyte information a day $\left(2.5 \times 10^{60}\right.$ bytes) since 2012, has led to the formation of fast, large-scale and complex data massive at all levels of society, which proves the beginning of the "scary big data" age [25, 26]. Big Data (BD) is a set of data, which is beyond the capabilities of the traditional database processing, collection, storage, management and analysis tools. In this sense, huge data processing by means of conventional systems is hard. That is why they are analyzed and processed in order to obtain important information by establishing the correlation between these data. This also requires the training of the specialties with knowledge and skills on BD. Table 1 describes the skills of this personnel by their categories [27]. The US base SAS analytical company forecasts that the need for BD specialists will increase by $160 \%$ in $2013-2020$, as a result, the number of jobs in BD will be increased by 346000 units reaching 1 million.

According to the recent studies, medicine is a field of science, in which extremely large amounts of data are accumulated, and $30 \%$ of collected and stored data throughout the world is health data [28]. Taking this into account, nearly 300000 BD experts must be trained for medicine. Thus, the availability of the group of leaders and the personnel capable to how, when, where, and better way use the medical data is the demand of the day. In [27], it is stated that this staff earned $£ 55,000$ per year, which is more than the salaries of IT professionals by $2 \%$. 
Table 1

Required staff qualifications on BD and their skills

\begin{tabular}{|c|c|c|}
\hline & Qualifications & Required Skills \\
\hline 1. & BD creator & $\begin{array}{l}\text { NoSQL, Java, JavaScript, MySQL and Linux together } \\
\text { with TDD, CSS and Agile development knowledge }\end{array}$ \\
\hline 2. & BD projectors & $\begin{array}{l}\text { Oracle, Java, SQL, Hadoop, and SQL } \\
\text { Server and Data Modelling, ETL, } \\
\text { Enterprise Architecture, Open Source and Analytics }\end{array}$ \\
\hline 3. & BD analysts & $\begin{array}{l}\text { Oracle, SQL and Java together with } \\
\text { Data Modelling, ETL, Analytics and Data Analysis }\end{array}$ \\
\hline 4. & $\mathrm{BD}$ administrator & $\begin{array}{l}\text { Linux, MySQL, Puppet, Hadoop and Oracle along with } \\
\text { Configuration Management, Disaster recovery, } \\
\text { Clustering and ETL }\end{array}$ \\
\hline 5. & $\mathrm{BD}$ project manager & $\begin{array}{l}\text { Oracle, Netezza, Business Objects and Hyperion together } \\
\text { with ETL, and Agile Software Development - PRINCE2 }\end{array}$ \\
\hline 6. & BD designer & $\begin{array}{l}\text { Oracle, SQL, Netezza, SQL Server, Informatica, MySQL } \\
\text { and Unix plus ETL, Data Modelling, Analytics, CSS, } \\
\text { Unit Testing, Data Integration and Data Mining. }\end{array}$ \\
\hline 7. & BD scientist & $\begin{array}{l}\text { Hadoop, Java, NoSQL and C++ along with Artificial } \\
\text { Intelligence, Data Mining and Analytics }\end{array}$ \\
\hline
\end{tabular}

\section{Training of personnel in e-health specialties in Russia}

Russia pays special attention to the personnel training for the formation of e-health. At many higher education institutions, the student enrollment in "medical cybernetics", who will realize the transformation of medicine and ICT is increasing year after year. Medical Cybernetics - is a field of science dealing with the use of Cybernetics, ideas, methods and technical tools in medicine and health care. The training of the professionals in "Medical cybernetics" is carried out at the following educational institutions of the Russian Federation:

- the Russian National Research Medical University after Piragov N.I. The training of this specialty started here for the first time in the department of medical biology;

- Siberian State Medical University (Tomsk);

- Penza State University;

- North-eastern Federal University (Arkhangelsk);

- Kazan (Privolzhsk) Federal University;

- Pskov State University;

- Krosnoyarsk State University after Prof. Voyno-Yasenetsk V.F.;

- South-Western State University (Kursk);

- Far Eastern Federal University (Vladivastok).

At present, "health cybernetics" is a complete medical and its owner is a physiciancybernetics scientist. physician-cybernetics scientist can not work as a surgeon, therapist and other senior medical specialist (doctor-clinician) or enter residency. The graduates can work at clinical laboratory, functional diagnostics, radiology, and in the field of medical physics.

Health Cybernetics can be presented in two groups: 
1. Mathematical diagnosis of diseases - is associated with the use of computer techniques in the data processing incoming from a biological object. In this case, the graduates of "health cybernetics" can work as the following physicians [29]:

- clinical laboratory diagnostics physician;

- X-ray doctor;

- Physician-bacteriologist;

- Physician-virologist;

- Physician-geneticist;

- Physician-mycologist;

- Physician-radiologist;

- $\quad$ Ultrasound diagnosis doctor;

- Functional diagnostics doctor.

The graduates of this specialty can work for the informatization of healthcare at medical institutions, health information-analytical centers, healthcare management centers, health insurance companies, including the companies developing and operating health information systems. They can also deal with the maintenance of medical diagnostic equipment.

2. Automated control systems and their capabilities in healthcare. The graduates of the specialty are able to achieve the knowledge in the following areas[30]:

- Development, application and use of automated health information systems;

- The use of computer techniques in the health data processing;

- The use of modern clinical laboratory, bio-physiological and bio-chemical devices at the laboratories and departments of the medical and scientific organizations;

- Verification of electronic-medical apparatus and basic troubleshooting;

- Receiving therapeutic, surgical and neurological patients, defining their main symptoms and syndromes to set the preliminary diagnosis;

- Drawing up a plan of laboratory and instrumental analysis;

- Conducting the researches in clinical laboratory, biochemistry, bio-physics, immunology and medical genetics;

- Appointing the diagnosis based on the results of the clinical, laboratory and instrumental studies, and selection of treatment tactics;

- Organization and planning of the medical staff;

- Organization of a variety of events related to the population's health, healthy lifestyles, environmental health effects, and the prevention of diseases;

- $\quad$ Providing emergency medical aid;

- Delivering the laboratory and practical lessons in natural sciences, biomedical and clinical subjects at higher education institutions and colleges;

- Developing scientific and methodological materials on the professional activity.

The professionals in this specialty should be ready for the solution of the following issues [31]:

- the development of public health planning and forecasting models with the use of mathematical methods and computational techniques;

- the use of mathematical methods and computational techniques for the solution of the statistical data processing;

- the development of the information support of the automated health care control system;

- the development of the functional system model of an organism - the physiological system of the separate human organs, and their use for the diagnosis of the patient's condition, automated control and forecasting with the use of information technology;

- the use of applied software packages for the solution of computing diagnosis and the detection of informative indicators out of the clinical data massive;

- the use of technology for the development of medical expert systems;

- diagnosing the diseases by mastering the instrumental and laboratory research methods; 
- providing diagnosis and first aid in the emergency situations;

- providing the medical aid to the population in the emergency situations as the epidemic spread, mass lesion and so on.

The subjects taught in this specialty are:

- computer science [32];

- information technologies in social sphere [33];

- computer science in psychology [34];

- health information systems;

- clinical cybernetics;

- clinical laboratory diagnostics;

- medical biophysics;

- medical electronics;

- general and medical radiobiology;

- system analysis and healthcare organization;

- theoretical basis of cybernetics;

- physiological cybernetics;

- functional diagnostics.

\section{e-health staff training in Azerbaijan}

"Medical physics and informatics" department is operating (formerly called "Medical and Biological Physics" (adjunct to the course of computer science and computer engineering) at the Azerbaijan Medical University. The subjects "Medical and Biological Physics", "Higher Mathematics" and "Computer science" are taught at this department. "Computer science" is taught at the 1 st course of the bachelor degree and the courses on the office programs are taught one term at the master degree.

Azerbaijan State University of Oil and Industry is training the staff on "Biomedical technology engineering". The Students, majoring in biomedical technology engineering, are taking the subjects, as biology, computer science, biophysics, medical methods of diagnosing, computer technologies, physics, computer and engineering graphics, information technology, biomaterials and so on. These students are taught how to practice new biomedical devices, to introduce new developments in the production, to set up and operate biomedical equipment, to develop new biomedical devices and tools (computer tomography, blood pressure measuring devices, etc.), and to realize the certification and attestation of new biomedical technology. The graduates of "Biomedical Technology Engineering" can work as an engineer, laboratory engineer, medical equipment engineer, and environmental protection engineer at treatment and diagnostic centers, medical-biological centers, clinics and other relevant institutions.

\section{Conclusion}

Drawing upon the experience of developed countries, below recommendations need to be considered for the preparation of respective workforce and human resources, which is the principal guarantee of the formation of E-health in Azerbaijan:

- demand for the personnel with the specialties appropriate to the E-health formation should be determined;

- short and long term strategies and programs, which provide the training of required qualifications, should be adopted;

- courses should be organized for the medical staff at different levels to develop their ICT knowledge and skills;

- parties interested in the identification of the skills and competencies necessary for the eHealth workers: government, educational institutions, medical and IT experts, educators should be involved in this work; 
- new educational programs and professional standards in the field of health informatics should be developed;

- qualifications should be recognized for the workforce recruitment, employee retention (motivation), and the stages of career growth shall be designed;

- relevant associations and centers should be established for the coordination of experts.

The realization of all above-mentioned items can be a successful step towards the integration of Azerbaijan into the international e-health environment.

\section{References}

1. Alguliyev R.M., Mahmudov R.Sh. The transformation issues of the market economy in the information society //Information Society Problems, 2013, No2, pp.31-41.

2. Candace J.Gibson, H. Dominic Covvey. Clinical technologies. Chapter 5.1. Demystifying ehealth human resources, 2011, pp.1403-1416,

http://www.irma-international.org/chapter/demystifying-ehealth-human-resources/53656/).

3. Eardley T. NHS Informatics Workforce Survey. 2006, ASSIST: London, England,http://www.bcs.org/upload/pdf/finalreport_20061120102537.pdf

4. Legg M, Lovelock B. A Review of the Australian Health Informatics Workforce. 2009, Health Informatics Society of Australia: Melbourne, Australia,

http://www.hisa.org.au/files/File/Australian_Health_Informatics_Workforce_Review_v1_1.pdf

5. O'Grady J. Health Informatics and Health Information Management: Human Resources Report. 2009, Prism Economics and Analysis: Toronto, Ontario, http://www.ictcctic.ca/uploadedFiles/Labour_Market_Intelligence/E-Health/HIHIM_report_E_web.pdf

6. Monegain B. Health IT effort to create thousands of new jobs, says Blumenthal, Healthcare IT News. October 6, 2009, http://www.healthcareitnews.com/news/health-it-effort-createthousands-new-jobs-says-blumenthal

7. Hersh W., Wright, A. Characterizing the health information technology workforce: Analysis for the HIMSS Analytics database, 2008, www.http://www.medir.ohsu.edu/ hersh/hitworkforce-hersh.pdf

8. Ozbolt J. An environmental scan: educating the health informatics workforce in the global South / In Making the ehealth Connection Conference, Bellagio, Italy, 2008, July 13-August 8, 2008. New York: Rockefeller Press.

9. Covvey, H. D., Zitner, D., \& Bernstein, R. M. Pointing the way: Competencies and curricula in health informatics, 2001, http://www.hi.uwaterloo.ca/hi/Resources.htm.

10. Monegain B. Healthcare IT: is it a breed apart? Healthcare IT News. September, 2004, http://www.healthcareitnews.com/story.cms?id=1522

11. Australia Department of Health and Aging. HealthConnect. Report on the health information workforce capacity think tank, 2003a, July 28, http://www.health.gov.au/internet/hconnect/publishing.nsf/Content/7746B10691FA666CCA257128007B7EAF/\$File/july03think.pdf

12. United Kingdom, National Health Services. Making Information Count: A Human Resources Strategy for Health Informatics Professionals, 2002, October, 40 p.

13. United Kingdom, National Health Services Connecting for Health: Professionalizing Health Informatics (PHI), 2009, http://www.connectingforhealth.nhs.uk/systemsandservices/capability/phi.

14. Coeira E. W. Lessons from the NHS national programme for IT // The Medical Journal of Australia, 2007, vol.186, no.1, pp.3-4.

15. Smith J. Wanted: Cyber clinicians to transform the nation's healthcare system bit by bit // Canadian Healthcare Manager, 2005, June, pp.13-14.

16. LaFleche C., Gardner N. Hitting the health informatics (HI) wall: A call to collaborative action on human resources // Healthcare Information Management \& Communications Canada (HCIM\&C), 2008, vol.22, no.3, pp.16-18. 
17. Seaton B. A great time to be a Health Informatics Professional... (and not so great if you need to hire one) // Healthcare Information Management \& Communications Canada (HCIM\&C), 2008, vol.22, no.2, pp.16-17.

18. Department of Health and Human Services. Nationwide Health Information Network (NHIN) workforce study: Final report, 2007, September 19, http://www.aspe.hhs.gov/sp/reports/2007/NHIN/NHINReport.shtml.

19. Wing P., Langelier M., Continelli T., Armstrong D. Data for decisions: The HIM workforce and workplace 2002 member survey, 2003, Chicago: American Health Information Management Association (AHIMA), http://www.library.ahima.org/xpedio/groups/public/documents/ahima/bok1_018947.pdf

20. Eysenbach G. What is e-health? // Journal of Medical Internet Research, 2001, vol.3, no.2, e20, http://www.jmir.org/2001/2/e20

21. Hersh W. The Health Information Technology Workforce //ApplClin Inform., 2010, vol.1, no.2, pp.197-212.

22. Department of Health and Human Services. Office of the National Coordinator for Health Information Technology. The ONC-Coordinated Federal Health IT Strategic Plan: 20082012, http://www.hhs.gov/healthit

23. American Health Information Management Association and American Medical Informatics Association. Building the work force for health information transformation. AHIMA: Chicago. 2006, Bethesda, http://www.amia.org

24. American Medical Informatics Association. Press Release- AMIA receives grant from Bill \& Melinda Gates Foundation to develop a global biomedical and health informatics fellowship program, 2008 December,

http://www.amia.org/files/Gates_GlobalFellowshipProgramPR.pdf

25. Big Data in Human Resource Management - Developing Research

Context,file:///C:/Users/HP/Downloads/Big\%20Data\%20in\%20Human\%20Resource\%20M anagement\%20.pdf

26. Mammadova M.H., Jabrayilova Z.G. Big Data opportunities and problems in the solution of human resource management issues // Information Technologies Problems, 2016, No1, pp.39-48.

27. SAS report on "Big Data Analytics Assessment of Demand for Labour and Skills 2013-2020, 2014, http://www.sas.com/en_us/home.html

28. Manchini M. Exploiting Big Data for improving healthcare servuces// Journal of e-Learning and Knowledge Society, 2014, v.10, n.2, pp.23-33.

29. Health Cybernetics at Pskov State University, questions and answers, http://www.pskgu.ru/page/6ACD44BF4D7BBA8C8E8483979E0BBE9C

30. http://www.cmci.rsmu.ru/

31. http://www.ee.swsu.ru/spec.php?SPEC_SHIFR=\%CC\%CA

32. http://www.cmci.rsmu.ru/fileadmin/rsmu/img/mbf/cmci/rab_programmi/up_informatika.pdf

33. http://www.cmci.rsmu.ru/fileadmin/rsmu/img/mbf/cmci/rab_programmi/up_it.pdf

34. http://www.cmci.rsmu.ru/fileadmin/rsmu/img/mbf/cmci/rab_programmi/up_i_i_evm.pdf 